\title{
Longitudinal Stability of Intellectual Functioning in Autism Spectrum Disorder: From Age 3 Through Mid-adulthood
}

\author{
Molly B. D. Prigge ${ }^{1}$ ( $)$ Erin D. Bigler, 2,3,45 Nicholas Lange $^{6} \cdot$ Jubel Morgan $^{1} \cdot$ Alyson Froehlich $^{7} \cdot$ Abigail Freeman $^{8}$.

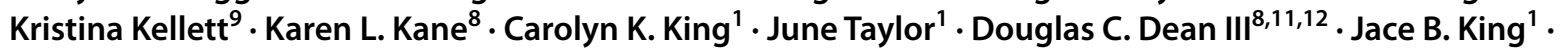 \\ Jeff S. Anderson ${ }^{1} \cdot$ Brandon A. Zielinski $^{3,10} \cdot$ Andrew L. Alexander ${ }^{8,12,13} \cdot$ Janet E. Lainhart ${ }^{8,13}$
}

Accepted: 29 July 2021 / Published online: 22 October 2021

(c) The Author(s) 2021

\begin{abstract}
Intelligence (IQ) scores are used in educational and vocational planning for individuals with autism spectrum disorder (ASD) yet little is known about the stability of IQ throughout development. We examined longitudinal age-related IQ stability in 119 individuals with ASD (3-36 years of age at first visit) and 128 typically developing controls. Intelligence measures were collected over a 20-year period. In ASD, Full Scale (FSIQ) and Verbal (VIQ) Intelligence started lower in childhood and increased at a greater rate with age relative to the control group. By early adulthood, VIQ and working memory stabilized, whereas nonverbal and perceptual scores continued to change. Our results suggest that in individuals with ASD, IQ estimates may be dynamic in childhood and young adulthood.
\end{abstract}

Keywords Autism spectrum disorder $\cdot$ ASD $\cdot$ Intelligence $\cdot$ Longitudinal study $\cdot$ Cognitive development $\cdot$ Stability

Measures of intelligence are important in the clinical evaluation of children and adults with Autism Spectrum Disorder (ASD) and in ASD research. Tests of intelligence, most commonly assessed as intelligence quotients (IQ) metrics or index scores, are typically obtained on all individuals who meet criteria for ASD because of the major implications for educational, vocational, and treatment planning and

MollyB.D. Prigge and ErinD. Bigler are joint first author

Molly B. D. Prigge

molly.prigge@hsc.utah.edu

1 Department of Radiology and Imaging Sciences, Radiology

Research, University of Utah, 729 Arapeen Drive,

Salt Lake City, UT 84108, USA

2 Department of Psychology and Neuroscience Center, Brigham Young University, Provo, UT, USA

3 Department of Neurology, University of Utah, Salt Lake City, UT, USA

4 Department of Psychiatry, University of Utah, Salt Lake City, UT, USA

5 Department of Neurology, University of California-Davis, Davis, CA, USA

6 Department of Psychiatry, Harvard School of Medicine, Boston, MA, USA understanding vulnerability to distressing emotional states (Kraper et al., 2017; Mayes \& Calhoun, 2003; Mayes et al., 2011; Pallathra et al., 2018; Solomon et al., 2018; Stewart et al., 2017; Tureck et al., 2014). Basic relations exist between level of intellectual functioning and social processing (Bishop-Fitzpatrick et al., 2017; Morrison et al., 2019); this relationship is a problematic area of cognitive processing and adaptive functioning in those with ASD (Kraper et al., 2017). Lower levels of intellectual functioning have

7 Department of Psychology, University of Utah, Salt Lake City, UT, USA

8 Waisman Center, University of Wisconsin-Madison, Madison, WI, USA

9 Department of Medicine, University of Wisconsin-Madison, Madison, WI, USA

10 Department of Pediatrics, University of Utah, Salt Lake City, UT, USA

11 Department of Pediatrics, University of Wisconsin-Madison, Madison, WI, USA

12 Department of Medical Physics, University of Wisconsin-Madison, Madison, WI, USA

13 Department of Psychiatry, University of Wisconsin-Madison, Madison, WI, USA 
been associated with higher levels of ASD symptom severity (Bishop et al., 2006; Charman et al., 2017; Mayes et al., 2011; Nordin \& Gillberg, 1998) and are one of the strongest childhood predictors of diagnostic and functional outcome in adulthood (D. K. Anderson et al., 2014; Howlin et al., 2004, 2014; Magiati et al., 2014). Psychometrically, IQ correlates positively with essentially all other cognitive metrics, particularly language and memory (Prigge et al., 2013; Southwick et al., 2011). A general intelligence factor, "g", is thought to mediate the interrelationships between all cognitive processes and IQ (Deary, 2012). Because a modest but positive correlation exists between IQ and regional brain volumes (Lange et al., 2010) and cortical thickness (Zielinski et al., 2014), psychometric computation of IQ scores has become an important matching and/or statistical control feature in neuroimaging research (Bigler, 2017). A better understanding of the IQ metric as assessed in individuals with ASD has broad implications for all facets of the condition.

Despite the importance of the IQ measure in the clinical care of individuals with ASD and in ASD research, very little is known about the stability of IQ longitudinally, especially during the transitions from childhood through adolescence and into adulthood (Martos-Perez et al., 2018). Crosssectional studies have examined IQ in those with ASD from childhood to adulthood (Charman et al., 2017; Tillmann et al., 2019) but do not inform on individual changes. Longitudinal childhood studies show that some ASD participants have stable IQ scores (within $\pm 1 \mathrm{SD}$ ), yet many individuals have scores that increase or decrease over time (see Begovac et al., 2009 for a review; Solomon et al., 2018). The few studies that have tested ASD participants in childhood and repeated testing in young adulthood report an overall gain of 7 points (Simonoff et al., 2019) and significant variability (Bishop et al., 2015; Lord et al., 2015). Some studies have shown a decline in IQ in $23-35 \%$ of the participants, while $18-33 \%$ of the participants show an increase in IQ scores from childhood to adulthood (Farley et al., 2009; Howlin et al., 2014). To date, limitations of longitudinal ASD studies of IQ across the lifespan include lack of a control sample, estimates of IQ scores from adaptive functioning, and most importantly, a limited number of time points per individual ( $\leq 3)$ from which to infer longitudinal change or stability. Additional waves of data, of 3 time points or more, add to the measurement of individual trajectories and reliability of estimated change at the group level by statistical regression models (Willett et al., 1998).

The longitudinal Interdisciplinary Science to Learn about Autism (ISLA) project is an NIH-funded study of how clinical phenotypes and multimodal brain images change over time in ASD individuals. The goal of ISLA is to understand central tendencies, variation in brain development and maturation and the relationship to variation in clinical course and adult outcome. To date, the project has focused on the subgroup of individuals with autism whose cognitive ability (nonverbal IQ) is $\geq 70$. Research has shown that adult outcome is poor to very poor in up to $60 \%$ of individuals in this subgroup (Howlin et al., 2013). In the ISLA study, participants were enrolled as young as 3 years of age and have been tracked to the current time frame; some participants have been followed and re-examined for more than 22 years with up to 7 time points of IQ data. Accordingly, we now describe the longitudinal trajectory and the stability of IQ scores in this ASD sample compared to age-matched, typically developing controls (TDC).

One challenge investigating IQ from childhood to adulthood is that its psychometric assessment is dependent on different standardized measurements that vary by age and language ability. When this investigation began, there was no universal IQ test that could be administered across the broad age-range of participants enrolled in the study, let alone over the next $20+$ years of life. Furthermore, over a longitudinal study of this length, tests are updated and revised to reflect age and demographic normative adjustments due to drift over time. IQ for the youngest children was assessed by using either the Mullen Scales of Early Learning (Mullen, 1995) or the Differential Ability Scales (DAS; Elliott, 1990), both of which are established measures in the assessment of young children with ASD (Akshoomoff, 2006; Bishop et al., 2011). Once the participant was 5 or 6 years of age, intellectual assessment was performed with the DAS or one of the Wechsler measures [Wechsler Intelligence Scale for Children, WISC-III (Wechsler, 1991) or Wechsler Abbreviated Scale of Intelligence, WASI; (Wechsler, 1999)]. Once participants reached 16 years of age, a Wechsler-based test was used (Wechsler, 1997, 1999, 2008). Regardless of the test administered, all of the IQ measures employed in the ISLA project are highly interrelated and provide similar domain metrics that permit comparison across time (Flanagan \& McDonough, 2018); using standardized IQ metrics from different tests becomes the practical solution when the identical test cannot be used in every instance, as is common practice in the real world (Bishop et al., 2011).

In the history of intellectual assessment, some core domains of functioning have emerged that encompass an overall or full-scale metric, assumed to characterize the level of aggregate intellectual performance. The Full Scale IQ (FSIQ) score, as a composite, is derived from verbal and non-verbal tasks and has age-adjusted norms with a mean of 100 (SD 15). Subdomains, while not all referred to as IQ scores, are nonetheless index scores with the same mean and SD, highly related to FSIQ but also representative of their own domain. Wechsler subset IQ or index scores have evolved over time and likewise influenced how other IQ tests categorize domains. These general domains include Verbal IQ (VIQ), Nonverbal IQ (NVIQ or Performance IQ), Verbal 
Comprehension Index (VCI), Perceptual Organization Index (POI), Working Memory Index (WMI) and Processing Speed Index (PSI) (Canivez et al., 2017; Wechsler, 1997). Within normative samples, IQ scores are assumed to stabilize by older adolescence and young adulthood, as shown by Salthouse (2016, 2019a, 2019b) and others (Hartshorne \& Germine, 2015). Although different instruments for assessing IQ were used across our study period, the general domains used by the Wechsler approach can also be extracted from the Mullen or DAS (Flanagan \& McDonough, 2018; Lezak et al., 2012). Thus, we have retained these classic intellectual and cognitive processing distinctions in terms of functional domains, although these non-Wechsler scales were administered to the youngest participants.

To our knowledge, ISLA is the first study to characterize intellectual functioning across more than 3 time points in most participants, spanning early childhood to mid-adulthood. We employed a straightforward method to investigate stability over time in ASD by plotting trajectories that link individual participants' time points and then aggregating these data to generate a visual depiction of measured group changes across age. By their design, age-normed longitudinal standardized IQ scores are not expected to change over time at the general population level. Given the mixed agerelated findings in studies to date, we tested the hypothesis that intelligence measures were stable over time in cognitively-able (nonverbal IQ $\geq 70$ ) individuals with ASD and would follow similar trends to those observed during typical development. We present statistical analyses of age-related changes for the entire ASD sample and then the subset of participants age 18 and older to examine stability in IQ scores throughout adulthood. We also asked whether or not IQ scores remained within a level of expected variability given inherent fluctuations in cognitive performance that naturally occur over time and known test-retest variability and practice effects. These sources of extraneous variation can cause an IQ score to deviate beyond its inherent variability (see Hinton-Bayre, 2016; Maassen et al., 2009). Finally, we explored the longitudinal trajectories of IQ in the subgroup of ASD individuals with highly discrepant NVIQ and VIQs ( $\geq 15$ points).

\section{Methods}

\section{Participants and Study Design}

ISLA uses an Accelerated Longitudinal Design, specifically, a mixed cross-sequential/

cohort-sequential strategy (Farrington, 1991). ASD participants were recruited from predominantly community and to a lesser extent clinical sources (namely parent support groups, youth groups, schools, and clinical social skills groups) into four age cohorts (3-6 years, 7-11 years, 12-18 years, and 19-39 years) and followed longitudinally; some participants had IQ scores from a prior study that began in 1997. For this report, we included all ASD and TDC participants with Intelligence measures collected from 1997-2018 (see Table 1). For comparison with other studies (D. K. Anderson et al., 2014; Howlin et al., 2013), only participants with at least one NVIQ score of 70 or above were included. Thus, of the 127 ASD participants tested, 5 participants were excluded because all available IQ scores were $<70$, and 3 participants were excluded due to all testing being completed over the age of 41 , and not overlapping in age with our TDC group. The resulting sample included 119 ASD participants (114 males, 5 females) and 128 TDC participants (122 males, 6 females). Ninety-nine (83\%) of the ASD participants and 55 (42\%) of the TDC participants were enrolled between 2002-2005; the remaining participants entered the study during subsequent years. All study procedures were approved by the University of Utah IRB.

ASD was diagnosed using DSM-IV (American Psychiatric Association, 1994) and ICD-10 criteria, and was based on assessment with the Autism Diagnostic Interview-Revised (ADI-R; (Lord et al., 1994), the Autism Diagnostic Observation Schedule (ADOS; (Lord et al., 1999) or ADOS-2 (Lord et al., 2012), and record review. Collaborative Programs of Excellence in Autism (CPEA) criteria (Lainhart et al., 2006) were used for an ADI-R classification of ASD. ADOS scores were converted to ADOS-2 algorithm scores and comparison scores on all ASD participants (Hus \& Lord, 2014; Hus et al., 2014). ADI-Rs and ADOS/ADOS- $2 \mathrm{~s}$ were administered by research-reliable clinicians and $\mathrm{PhD}$-level research staff. ASD participants met criteria for a classification of ASD on both the ADI-R and ADOS-2 at study entry, with the exception of 2 older participants who met ADI-R criteria and whose records were consistent with a lifetime diagnosis of ASD, but their current ADOS scores were subthreshold. ASD was idiopathic in all cases; known medical causes of ASD were excluded (Lange et al., 2015).

We compared longitudinal intelligence measures in our ASD group to measures in our TDC group. The TDC group helped account for possible changes in intelligence scores over time related to (a) different tests used, particularly in childhood versus adulthood (see below), (b) secular changes, (c) intelligence score inflation, and (d) site-specific effects. All TDC participants were assessed with the ADOS/ ADOS-2 to rule out ASD, they had to score within 1 SD of the mean on standardized tests of IQ, language, memory, and adaptive function, and they had no history of developmental, neurological, or psychiatric disorder. Beginning in 2007, we tried to enrich the non-ASD sample for children with IQs between 70-84, but only one of the many children in this IQ range who we assessed was otherwise "typically" developing and thus included in this study. 
Table 1 Participant Characteristics

\begin{tabular}{|c|c|c|c|c|c|}
\hline & \multicolumn{2}{|l|}{$\begin{array}{l}\text { ASD } \\
\mathrm{n}=119\end{array}$} & \multicolumn{2}{|l|}{$\begin{array}{l}\text { TDC } \\
\mathrm{n}=128\end{array}$} & \multirow[b]{2}{*}{ t-value } \\
\hline & Mean (SD) & Range & Mean (SD) & Range & \\
\hline Initial Visit: age in years & $14.2(8.1)$ & $3.1-36.8$ & $20.8(8.5)$ & $3.6-39.7$ & $6.2(\mathrm{p}<.001)$ \\
\hline \multicolumn{6}{|l|}{ Initial Visit: \% sample } \\
\hline Early Childhood (3-6 years) & $24 \%$ & & $6 \%$ & & \\
\hline Middle Childhood (7-11 years) & $24 \%$ & & $13 \%$ & & \\
\hline Late Childhood (12-18 years) & $26 \%$ & & $15 \%$ & & \\
\hline Adulthood $(19+$ years $)$ & $26 \%$ & & $66 \%$ & & \\
\hline All Visits: age in years & $19.6(9.0)$ & $3.1-46.4$ & $20.1(8.1)$ & $3.6-39.7$ & 0.7 (ns) \\
\hline \multicolumn{6}{|c|}{$\%$ Sample with IQ Discrepancy at Time 1} \\
\hline NVIQ $>$ VIQ $\geq 15$ & $24 \%$ & & $5 \%$ & & \\
\hline VIQ $>$ NVIQ $\geq 15$ & $13 \%$ & & $14 \%$ & & \\
\hline \multicolumn{6}{|l|}{ Parental Education (yrs) } \\
\hline Mother's & $15.6(2.0)$ & $12-21$ & $15.7(2.4)$ & $12-21$ & 0.1 (ns) \\
\hline Father's & $16.7(2.6)$ & $12-24$ & $16.8(2.6)$ & $12-23$ & $0.2(\mathrm{~ns})$ \\
\hline ADI-R Social & $19.5(5.6)$ & $8-30$ & & & \\
\hline ADI-R Communication & $15.4(4.3)$ & $7-25$ & & & \\
\hline ADI-R RRB & $7.0(2.3)$ & $3-12$ & & & \\
\hline ADOS-2 Total CSS & $8.2(1.6)$ & $2-10$ & & & \\
\hline ADOS-2 SA CSS & $8.1(1.5)$ & $2-10$ & & & \\
\hline ADOS-2 RRB CSS & $7.6(1.9)$ & $1-10$ & & & \\
\hline
\end{tabular}

Two of the ASD participants had ADOS Total scores below the ASD cutoff of 8 at time of study entry, resulting in low CSS scores. Review of early clinical data combined with ADI-R confirmed lifetime diagnosis of ASD

ADI Autism Diagnostic Interview-Revised; ADOS Autism Diagnostic Observation Scale; CSS ADOS-2 calibrated severity score; $S A$ Social Affect; RRB Restricted and Repetitive Behaviors

\section{Intelligence Tests}

At each timepoint, intelligence testing was obtained as part of a larger neuropsychological battery. At Timepoint 1, IQ tests for child participants ( $\leq 16$ years) were based on age and language ability (Mullen vs DAS). Scores obtained from testing prior to Timepoint 1 and all subsequent timepoints included only Wechsler based tests. Table 2 summarizes the tests used to measure intelligence across the cohorts and within individual participants. These measures provide repeated estimates of FSIQ, NVIQ, and VIQ, VCI, POI, WMI, and PSI. To examine changes in general intelligence measures over time, FSIQ obtained from the Wechsler tests was combined in the same analysis with the General Conceptual Ability Score (GCA) of the DAS and Early Learning Composite from the Mullen. The DAS Verbal Cluster was the best estimate of Wechsler VIQ. The Special Nonverbal Composite of the DAS (School and Lower Preschool versions) and Nonverbal Cluster from the DAS Upper Preschool forms were used as NVIQ estimates. For different Wechsler versions, the WAIS-IV (Wechsler, 2008) VCI was used as the WAIS-III/WISC-III VIQ and VCI equivalents, WAIS-IV Perceptual Reasoning
Table 2 Number of Intelligence Tests Administered

\begin{tabular}{|c|c|c|}
\hline & $\begin{array}{l}\text { ASD group } \\
436 \text { tests } / \mathrm{n}=119 \\
\# \text { tests/\# participants }\end{array}$ & $\begin{array}{l}\text { TDC group } \\
222 \text { tests/n=128 } \\
\# \text { tests/\# participants }\end{array}$ \\
\hline Mullen & $1 / 1$ & 0 \\
\hline DAS-Preschool & $17 / 17$ & $3 / 3$ \\
\hline DAS-School Age & $42 / 42$ & $26 / 26$ \\
\hline WISC-III & $36 / 32$ & $10 / 10$ \\
\hline WASI & $175 / 84$ & $95 / 49$ \\
\hline WAIS-III & $134 / 100$ & $88 / 86$ \\
\hline WAIS-IV & $31 / 31$ & 0 \\
\hline
\end{tabular}

Mullen Mullen Scales of Early Learning (Mullen, 1995), DAS Differential Ability Scales (Elliott, 1990), WISC Wechsler Intelligence Scale for Children (Wechsler, 1991), WASI Wechsler Abbreviated Scale of Intelligence (Wechsler, 1999), WAIS Wechsler Adult Intelligence Scale (Wechsler, 1997, 2008)

Index as WAIS-III/WISC-III NVIQ and POI estimates, and WISC-III Following Directions Index as WAIS-III/WAISIV WMI equivalent. A master table summarizing intelligence measures and index scores broken down by test 
version is provided as an online Supplementary Table. All intelligence tests were administered by clinical research scientists and graduate-student research staff, trained and supervised by senior clinical research neuropsychologists.

As mentioned in the Introduction, the challenge of the current investigation in obtaining typical and reliable change indices is that the same intellectual assessment instrument was not used across all participants and time points. To address this, we sought a practical solution by using general clinical decision rules where practice guidelines assume that repeated IQ scores within \pm 0.5 SD are within a cone of normal variability, representing fluctuations of no particular clinical importance (Lezak et al., 2012). We applied this rule to the current dataset and examined the frequency of IQ scores that deviated beyond $\pm 0.5 \mathrm{SD}$, using the initial IQ score as baseline or middle IQ score as an "anchor" in those with more than 2 scores. A second approach used the actual $95 \%$ confidence interval (CI) derived from the Wechsler-based IQ scores. Because all IQ measures used were based on a mean of 100 and a SD of 15 , using this approach permitted comparison of the IQ metric regardless of which test procedure was used in obtaining the IQ score.

\section{Statistical Analysis}

Linear mixed effect models (Laird \& Ware, 1982; Lange \& Laird, 1989) were employed to compare longitudinal changes in IQ scores over time in the ASD group to those in the TDC group. This strategy allowed for different numbers of testing occasions across participants, and it allowed inclusion of individual random intercepts and slopes for all participants. Each intelligence measure was modeled with a fixed component accounting for the linear effects of age, group, an age*group interaction, and for a quadratic effect of age and its interaction with group. Best fitting models were identified by the Akaike Information Criterion (Akaike, 1974). For each analysis, age was mean centered (combined ASD + TDC sample) and a Bonferroni correction was applied (significant $<0.05 / 7=0.007$ ) to account for the seven intelligence indices being analyzed. Longitudinal changes in NVIQ-VIQ discrepancy scores were also examined using mixed models. We then examined the stability of intelligence scores within individuals with ASD by calculating intraclass correlation coefficients (ICCs) and reporting the percentage of participants with repeated testing scores within \pm 0.5 SD and $95 \%$ Confidence Intervals (CIs) of established testing norms. All mixed effects models were run using the nlme package in $\mathrm{R}$ (Pinheiro et al., 2017; R Core Team, 2017), ICCs calculated using the R package ICC (Wolak et al., 2012).

\section{Results}

\section{Descriptive Statistics}

Mean age at the time of first IQ measurement was lower in the ASD group compared to the TDC group, but mean participant age across all tests collected did not differ between groups [see Table 1 and Supplementary Fig. 1 for age distribution of participants into age cohorts of early childhood (3-6 years), middle childhood (7-11 years), adolescence (12-18 years) and adulthood (19+ years)]. ASD and TDC groups were well-matched on parental education.

Most (77\%) of the 99 ASD participants and $56 \%$ of the 55 TDC participants in the original cohort recruited into the longitudinal study between 2002-2005 had $\geq 3$ time points of IQ data and 69\% ASD and 30\% TDC with $\geq 4$ time points. Participants recruited after 2005 had fewer time points of data, resulting in $68 \%$ of the total ASD sample and $24 \%$ of the TDC sample with $\geq 3$ IQ data points and $58 \%$ of ASD and $13 \%$ TDC with $\geq 4$ data points. The lower rate of repeated IQ measures in the TDC sample decreased the reliability of the longitudinal TDC IQ trajectories at the group level compared to the ASD trajectories (Willett et al., 1998). Nevertheless, the TDC group's IQ trajectories generally show relative stability of mean scores, which is to be expected given that IQ tests are normed for all ages. To ensure that trajectories of the ASD IQ curves were not influenced by more severe cases having fewer IQ scores, we compared ASD participants with and without $\geq 4$ time points of data; the 2 groups did not differ on mean age at first test $(\mathrm{t}=1.4)$, first FSIQ score $(\mathrm{t}=0.58)$, parental education (mother $\mathrm{t}=2.1$, father $\mathrm{t}=1.8)$, or ADOS total calibrated severity score $(\mathrm{t}=1.6)$. Due to the wide age range of participants, we also examined whether or not ADI Algorithm scores differed in the participants who were children (3-17 years) vs adults (18 years+) at study entry. We found similar Communication $(t=0.01)$ and Restricted, Repetitive Behavior scores $(t=0.3)$ yet higher Social Interaction scores in the adult group (mean $=22.6$, child mean $=18.9 ; \mathrm{t}=2.6, \mathrm{p}=0.02$ ). None of our ASD participants became untestable over time.

\section{Longitudinal Trajectories of IQ and Index Scores in ASD}

Figure 1 depicts the longitudinal IQ scores and age-related changes in both the ASD and TDC groups. FSIQ, VIQ, NVIQ scores were available for all ages and POI, VCI, WMI and PSI were available for participants 6 years and up. Table 3 contains the parameter estimates from the 

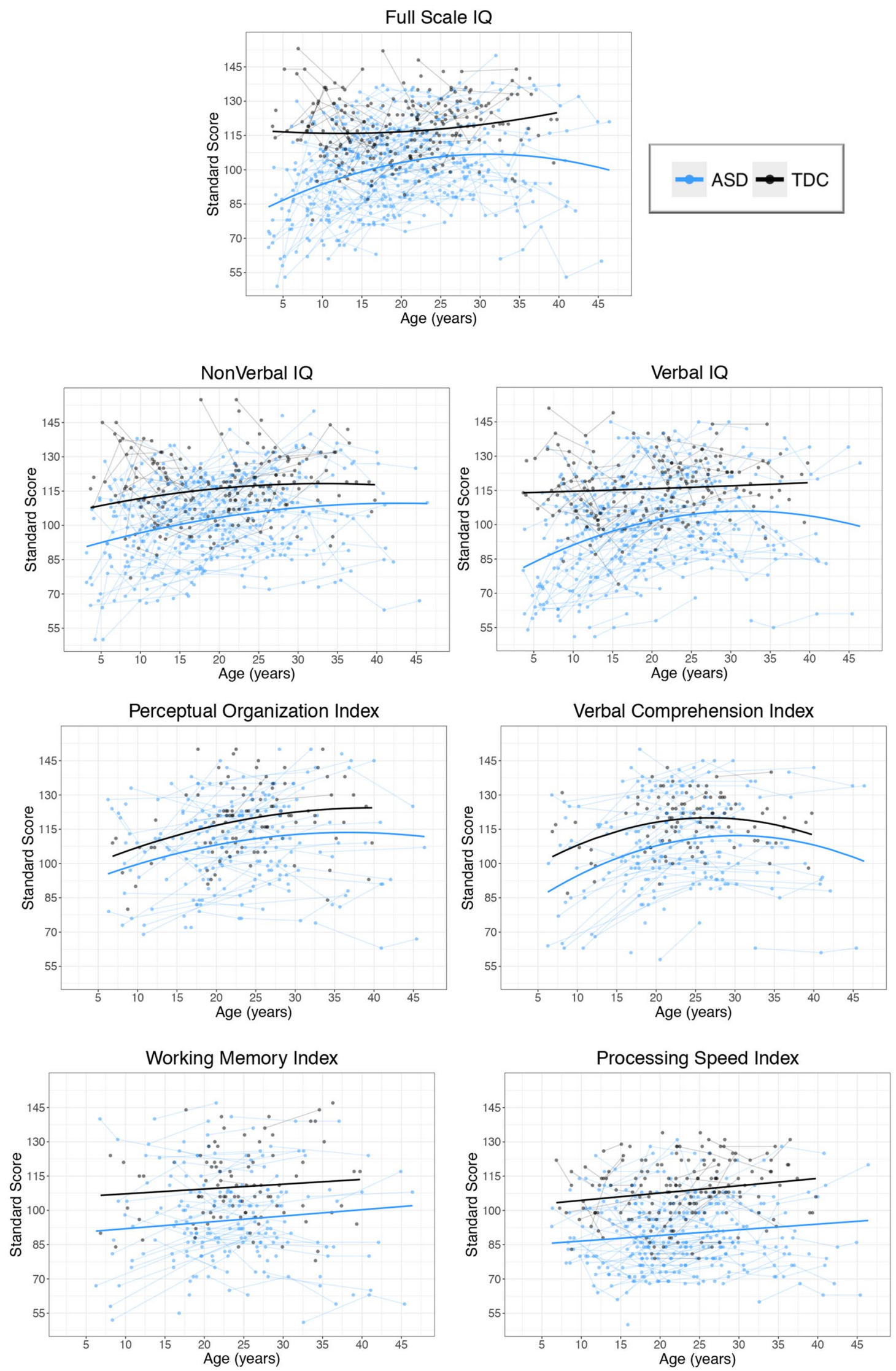

Fig. 1 Longitudinal changes in intelligence scores over time in ASD and TDC 
Table 3 Parameter Estimates from the Mixed Effects Models

IQ scores: Mullen, DAS, WISC-III, WAIS-III, WAIS-IV, WASI

\begin{tabular}{lllllll}
\hline & ASD Intercept & Group & Age & Age $^{2}$ & Group x Age & Group x Age $^{2}$ \\
\hline FSIQ & 103.0 & $13.5 * * *$ & $0.67 * * *$ & $-0.03 * * *$ & $-0.49 * * *$ & $0.04 * * *$ \\
VIQ & 101.6 & $14.1 * * *$ & $0.74 * * *$ & $-0.03 * * *$ & $-0.61 * * *$ & 0.03 \\
NVIQ & 103.3 & $12.7 * * *$ & $0.55 * * *$ & -0.01 & -0.23 & \\
\hline
\end{tabular}

Index scores: WISC-III, WAIS-III, WAIS-IV

\begin{tabular}{llllll}
\hline & ASD Intercept & Group & Age & Age $^{2}$ & Group x Age $^{\text {Group x Age }^{2}}$ \\
\hline VCI & 110.1 & $9.4 * * *$ & $0.60^{* * *}$ & $-0.04 * * *$ & -0.30 \\
POI & 110.0 & $8.9 * * *$ & $0.53 * * *$ & -0.02 & 0.12 \\
WMI & 95.8 & $14.3 * * *$ & 0.27 & & -0.06 \\
PSI & 89.7 & $18.7 * * *$ & 0.25 & 0.07 \\
\hline
\end{tabular}

ASD group is the reference group. $* * * \mathrm{p}<0.007$ (significant at $\mathrm{p}<0.05$ after Bonferroni correction)

FSIQ Full Scale Intelligence Quotient, VIQ Verbal Intelligence Quotient, NVIQ Performance Intelligence Quotient, VCI Verbal Comprehension Index, POI Perceptual Organization Index, WMI Working Memory Index, PSI Processing Speed Index

fitted mixed effects models examining age-related changes in ASD and group by age interactions. Visual inspection of Fig. 1 across the different IQ metrics examined, along with their quantitative analyses, shows the expected lower mean intelligence quotients and also lower index scores in the ASD group compared to the TDC group. After controlling for multiple comparisons, we found that all scores increased significantly with age in the ASD group except for WMI and PSI. FSIQ and VIQ started lower in the youngest cohorts of ASD participants and increased at a greater-than-typical rate with age. Our PSI findings replicate and expand on the subgroup of participants with up to 3 time points described previously (Travers et al., 2014).

Within-individual trajectories of the TDC participants supports the well-known increased instability of high-IQ scores during childhood and regression toward the mean, in which extreme values observed on the first measurement of a phenomenon "regress" toward the population mean on subsequent measurements (Galton, 1889; Rinaldi \& KarmiloffSmith, 2017). The large differences in the estimated values of the ASD and TDC longitudinal trajectories at the youngest and oldest ages are based on smaller amounts of IQ data and are best interpreted with caution.

\section{Adult Group Only}

To examine whether or not age-related changes were driven only by the younger ASD participants or persisted within the adult ages, we reran the models summarized in Table 3 but only included participants age 18 years and older at test date (ASD $n=93,227$ test visits; TDC $\mathrm{n}=98,132$ test visits; mean age in years $\mathrm{ASD}=26.6$ years, $\mathrm{TDC}=25.6, \mathrm{t}=1.5 \mathrm{p}=\mathrm{ns})$. All versions of the Wechsler tests WAIS-III, WAIS-IV, or WASI were present in the adult subgroup. In our adult ASD sample, age was significantly related to increasing standard scores of FSIQ, NVIQ, POI and PSI (Age effects: FSIQ $\beta=0.80 \mathrm{p}<0.001$, NVIQ $\beta=0.85 \mathrm{p}<0.001$, POI $\beta=0.72 \mathrm{p}<0.001$, PSI $\beta=0.49 \mathrm{p}<0.006)$. In contrast to the whole group analysis, we no longer found significant age effects for VIQ and VCI and continued to find no age effect for WMI (VIQ $\beta=0.17 \mathrm{p}=\mathrm{ns}$, VCI $\beta=0.28 \mathrm{p}=\mathrm{ns}$, WMI $\beta=0.06 \mathrm{p}=\mathrm{ns}$ ). There were no longer significant group*age interaction effects for FSIQ and VIQ (FIQ $\beta=0.006$, VIQ $\beta=-0.19$ ). These findings suggest stable VIQ and WMI scores during adulthood in ASD. Adult trajectories are presented in Supplementary Fig. 2.

\section{Longitudinal IQ Trajectories in ASD at the Level of Individuals}

Figure 2 displays the estimated change over time for FSIQ, NVIQ and VIQ in those ASD participants with $\geq 4$ IQ datapoints. Individual curves were predicted from the contributions of the fixed and random effects from the mixed effects models. Variability between individuals is evident, with some participants showing scores that increase over time, some are stable over time, and others slightly decline. Examination of within-individual trajectories of the ASD participants did not show evidence of a subgroup with sustained significant atypical age-dependent decline of $\geq 15$ points across developmental periods or in adulthood. We have provided a figure showing the relationship between random intercepts and slopes in those participants with both childhood and adulthood scores as Supplementary Fig. 3. 

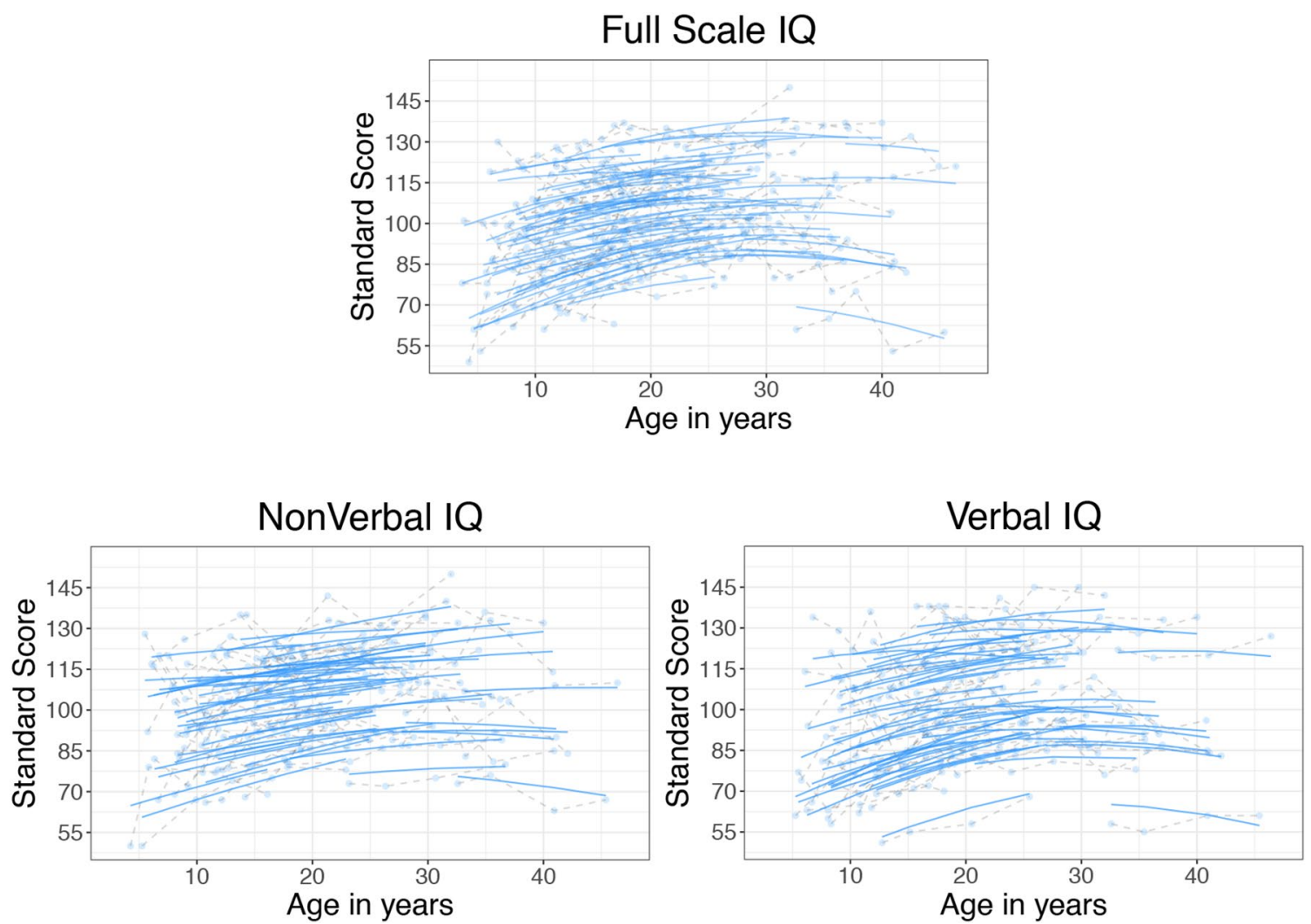

Fig. 2 Individual predicted change estimates for ASD participants with 4+ time points

\section{Longitudinal Changes in NVIQ > VIQ Discrepancy in ASD at the Subgroup Level}

NVIQ $>$ VIQ discrepancy in ASD is associated with large head size, increased impairment in social functioning, and a decreased rate of loss-of-function mutations and copy number variants in ASD-associated gene loci compared to ASD individuals without discrepant IQs (Bishop et al., 2017; Deutsch \& Joseph, 2003; Joseph et al., 2002). We explored the longitudinal trajectory of NVIQ > VIQ discrepancy in this hypothesized neurobiological cognitive subtype of ASD. Twenty-eight of the ASD participants (24\%) had NVIQ 15 or more points higher than VIQ when first tested and 16 participants (13\%) had VIQ 15 or more points higher than NVIQ. As evident in Fig. 3, the NVIQ > VIQ subgroup of participants showed a significant decrease in NVIQ-VIQ discrepancy score with age that was not found in the rest of the ASD group (group*age interaction $\beta=0.75, p<0.0002$ ) or TDC participants (group*age interaction $\beta=0.7, p=0.001$ ). A post-hoc analysis showed that the decrease in magnitude of the NVIQ > VIQ discrepancy with age in this subgroup was driven by an increase in VIQ with age above that found in the non-discrepant IQ ASD group. Supplementary Fig. 4 shows the versions of IQ tests administered over time within the ASD discrepant subgroups.

\section{Stability of Within-Individual IQ Scores Over Time}

We examined stability of IQ and index scores over time by calculating ICCs for the ASD and TDC participants (all ages, all IQ tests) with repeated testing (see Table 4). In the ASD group, ICCs ranged from 0.75 for NVIQ to 0.85 for WMI. In the TDC group, ICCs ranged from 0.58 for NVIQ to 0.74 for FSIQ (see ICC column in Table 4). Although ICCs were in general higher in ASD, there were also a greater number of participants with repeated tests available for analysis.

To reduce extraneous variability in test score that may be due to instrument version or change over developmental period (child to adolescent to adult) we then examined stability of IQ scores over time in our ASD participants with more than one full adult Wechsler testing session (WAISIII or WAIS-IV, participants age $16+$ years). Out of the 50 ASD participants with repeated full Wechsler testing, 2 tests were available from 37 participants, 3 tests from 12 participants and 4 tests from one participant, with an average intersession interval of 7.6 years (range 1.8-15.1 years). Only 2 TDC participants had repeated full Wechsler testing and are not reported. ICCs for the ASD scores increased from the full sample reported in Table 4: FSIQ $=0.91, \mathrm{NVIQ}=0.84$, $\mathrm{VIQ}=0.92, \mathrm{VCI}=0.90, \mathrm{POI}=0.86, \mathrm{WMI}=0.92$. Similar to 
Fig. 3 NVIQ-VIQ discrepancy score changes in ASD subgroups
Table 4 The Number of Participants with Repeated Intelligence Scores

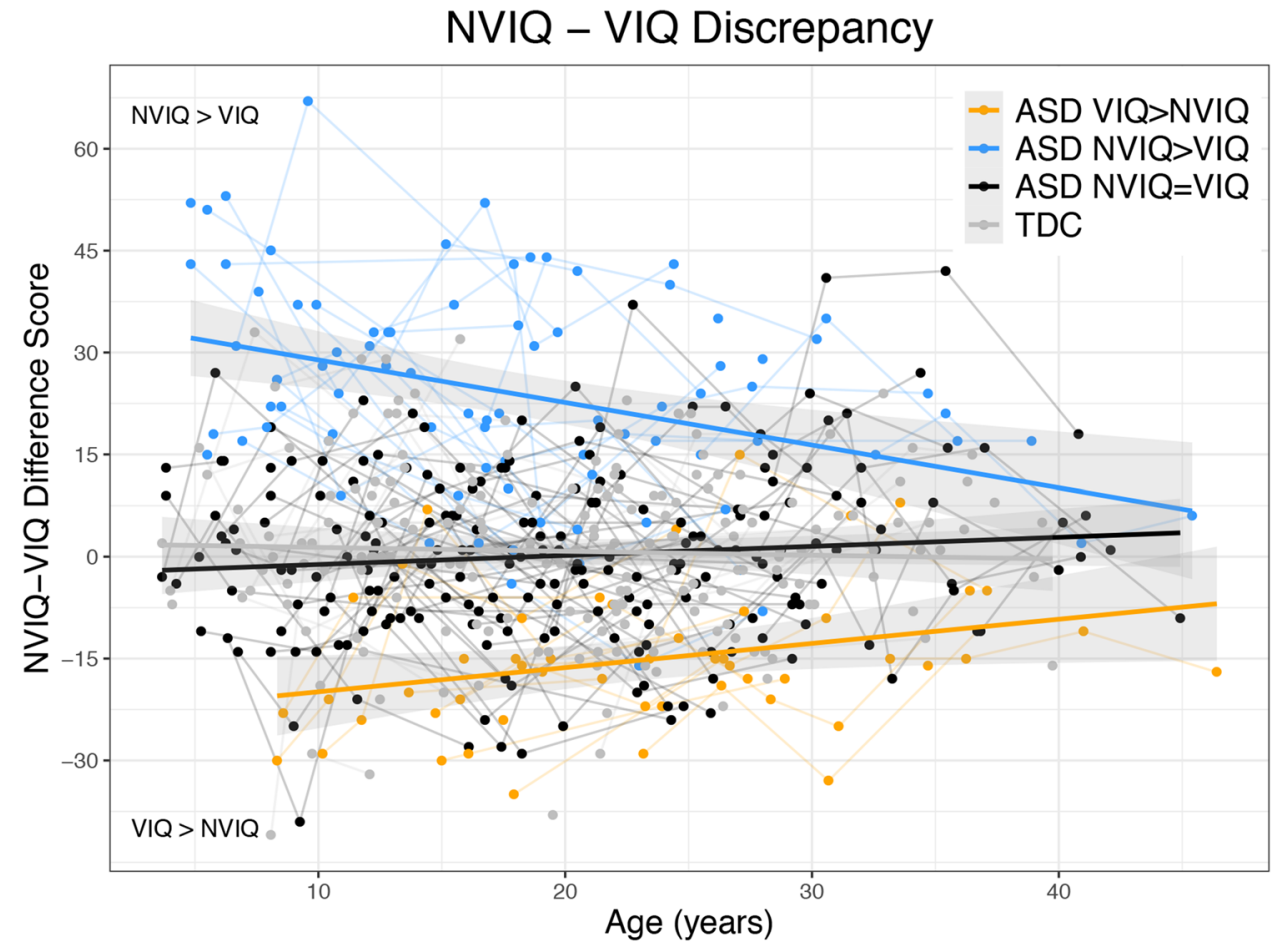

\begin{tabular}{|c|c|c|c|c|c|c|c|c|c|c|c|c|c|}
\hline & \multicolumn{7}{|c|}{ ASD } & \multicolumn{6}{|c|}{ TDC } \\
\hline & $2^{*}$ & 3 & 4 & 5 & 6 & 7 & ICC & $2 *$ & 3 & 4 & 5 & 6 & ICC \\
\hline FSIQ & 16 & 12 & 17 & 36 & 14 & 2 & 0.80 & 15 & 15 & 15 & 1 & & 0.74 \\
\hline VIQ & 22 & 18 & 34 & 14 & 5 & & 0.78 & 19 & 18 & 2 & & & 0.76 \\
\hline NVIQ & 23 & 20 & 34 & 14 & 5 & & 0.75 & 19 & 18 & 2 & & & 0.58 \\
\hline VCI & 33 & 21 & 5 & 1 & & & 0.78 & 2 & & & & & \\
\hline POI & 33 & 21 & 5 & 1 & & & 0.78 & 2 & & & & & \\
\hline WMI & 34 & 21 & 2 & & & & 0.85 & 2 & & & & & \\
\hline PSI & 23 & 32 & 23 & 6 & & & 0.81 & 27 & 8 & & & & 0.74 \\
\hline
\end{tabular}

*For example, FSIQ was collected 2 times on 16 ASD participants and 15 TDC participants.

ICC Intraclass Correlation Coefficient, FSIQ Full Scale Intelligence Quotient, VIQ Verbal Intelligence Quotient, NVIQ Performance Intelligence Quotient, VCI Verbal Comprehension Index, POI Perceptual Organization Index, WMI Working Memory Index, PSI Processing Speed Index the adult mixed model results discussed previously, higher ICCs and more stable IQ metrics were found in the verbal and working memory domain. Repeated PSI scores from the WAIS-III or WAIS-IV were available for 79 ASD and 25 TDC participants. Two scores were available on 26 ASD and 18 TDC, 3 scores on 34 ASD and 7 TDC, 4 scores on 16 ASD and 5 scores on 3 ASD (inter-session interval: ASD range $1.0-8.8$ years, average 4.7 years; TDC range 1.8-8.2 years, average 3.9 years). The PSI ICC was 0.84 in ASD and 0.79 in TDC.

Test stability was also measured by confidence intervals (CIs). The 95\% CIs provided in Appendix A of the WAIS-III manual were calculated around the first score in those with only 2 tests or middle score in those with more than 2 tests. Both WAIS-III and WAIS-IV tests were combined for this analysis. Table 5 is a display of the percentage of participants with repeated test scores falling within these CIs. For the participants age $16+$ years with repeated PSI scores $(n=79$ ASD, $\mathrm{n}=25$ TDC), the percentage of participants within certain CIs was similar for the ASD and TDC groups. 
Table 5 Percentage of ASD Participants Age 16+ with Repeated Full Wechsler Test Scores that Fell within Certain CIs

\begin{tabular}{llllll}
\hline & \multicolumn{2}{l}{ One SD CI $( \pm 7.5$ points $)$} & & \multicolumn{2}{l}{ WAIS-III 95\% CI } \\
\cline { 2 - 3 } \cline { 5 - 6 } & $\begin{array}{l}\text { All scores } \\
\text { within CI }\end{array}$ & $\begin{array}{l}\text { No scores } \\
\text { within CI }\end{array}$ & & $\begin{array}{l}\text { All scores } \\
\text { within CI }\end{array}$ & $\begin{array}{l}\text { No scores } \\
\text { within CI }\end{array}$ \\
\hline FSIQ & $63 \%$ & $27 \%$ & & $33 \%$ & $59 \%$ \\
PIQ & $51 \%$ & $35 \%$ & & $45 \%$ & $39 \%$ \\
VIQ & $59 \%$ & $33 \%$ & & $45 \%$ & $47 \%$ \\
VCI & $57 \%$ & $33 \%$ & & $47 \%$ & $45 \%$ \\
POI & $59 \%$ & $37 \%$ & & $47 \%$ & $43 \%$ \\
WMI & $63 \%$ & $33 \%$ & & $55 \%$ & $39 \%$ \\
PSI & $50 \%$ & $22 \%$ & & $65 \%$ & $14 \%$ \\
\hline
\end{tabular}

FSIQ, PIQ, VIQ, VCI, POI, WMI: N=50 ASD; PSI: N=79 ASD. Confidence Intervals (CIs) were calculated around the first test score in those with only 2 scores or middle score in those with $3+$ tests available. WAIS-III CIs were used for those participants with WAISIV scores

\section{Discussion}

Our cognitively-able ASD sample demonstrated distinct differences in comparison to our age- and SES-matched TDC sample. First, the longitudinal trajectory of IQ differed in the ASD group compared to the TDC group. Mean IQ started lower than typical in early childhood, increased during childhood and adolescence, and continued to increase in young adulthood. Second, the trajectories of WMI and PSI were flat during childhood and adolescence in the ASD group and only PSI showed some increase in young adulthood. Third, in the subgroup of ASD participants with NVIQ significantly greater than VIQ when first tested, the IQ discrepancy decreased with age. Fourth, despite the different IQ tests used across age and developmental periods in this study, similar to repeated testing to estimate intellectual functioning from childhood into adulthood for clinical, educational, and vocational planning purposes, the test-retest stability over long periods was overall good, more so for VIQ than NVIQ. However, even after 16 years of age, we found significant within-individual variability: over $50 \%$ of ASD participants with repeated IQ testing had at least one IQ falling outside the $95 \%$ confidence interval. Fifth, when longitudinal individual IQ trajectories were plotted for participants with 4 or more time points of IQ measures, we did not observe a significant, sustained, age-related decrease in IQ from childhood to adolescence to adulthood or in adulthood in any ASD participants.

\section{Longitudinal Trajectory of IQ and Index Scores in ASD at the Group Level}

The longitudinal trajectory of standardized IQ and some Index Scores at the group level in ASD is compatible with brain plasticity during childhood and even into young adulthood. ASD participants showed significantly lower IQ levels compared to those of TDC participants; this discrepancy was most evident in the younger ASD participants. As seen in Fig. 1, a substantial number of ASD participants had IQ scores below 85 , which is one SD below the mean, whereas only a few TDC participants had IQ scores at or below that level. Because statistical analyses demonstrated that FSIQ and VIQ increased at a greater rate with age in the ASD group than TDC participants, it may be that at the earliest age, the IQ discrepancies between ASD and TDC are at their greatest. Because some component of communication impairment is present for the diagnosis of ASD, this impairment may be more associated with verbal processes. This in turn is reflected in the lowest VIQ scores for the youngest ASD participants with the steepest increases when compared to NVIQ. It has long been discussed that deficits in VIQ may be more likely to accompany the diagnosis of ASD than NVIQ, although this distinction is not always observed (Charman et al., 2011).

Recently, Solomon et al. (2018) examined intellectual development in an ASD sample of 102 children from 2 to 8 years of age. From initial study recruitment to age 8 , over half of the children displayed improved intellectual scores, whereas approximately one-quarter showed decline. The Solomon study only examined ASD participants, so no similar comparison with TDC could be made. Figure 1 and our mixed model findings show that age-related increases in FSIQ and VIQ were driven by our child and adolescent participants. This finding is consistent with a recent populationbased study of ASD children from 10-12 to 23 years of age (Simonoff et al., 2019). In Fig. 1, while overall intellectual functioning and the various index scores show increases with age, the curves of the ASD and TDC groups never intersect for FSIQ, VIQ and NVIQ, suggesting that reduced intellectual functioning at the group level for those with ASD is a common observation.

\section{Longitudinal Trajectory of IQ in ASD at the Individual Level}

The longitudinal trajectories of IQ at the level of individuals with ASD in our sample suggest that despite betweenindividual variability, IQ does not significantly decline with age in a sustained manner from childhood to mid-adulthood in otherwise intellectually able individuals with autism. The finding is consistent with what is observed clinically in the rare case of an individual with ASD with a true sustained significant decrease in IQ over time: rather than being a feature of medically uncomplicated ASD, the individual may have developed a seizure disorder, a severe psychiatric disorder such as severe depression, or another medical condition that impacts cognition. 
A substantial number of individuals with ASD in our study had high IQ scores that completely overlapped with TDC participants who achieved the highest possible levels of the IQ tests. Preliminary evidence on a small sub-sample of individuals with ASD who had high IQs in young adulthood suggests that higher VIQ during early childhood predicts higher adult functional outcome (Lord et al., 2020; Pickles et al., 2020). Nevertheless, what Kraper et al. (2017) wrote continues to hold true: "For individuals with autism spectrum disorder (ASD), long-term outcomes have been troubling, and intact IQ has not been shown to be protective" (p. 3007). While average to above average intellectual ability is a highly valued attribute, the neural deficits that underlie social cognition and emotional control may be far more important for actual adaptive functioning than IQ (see Mazefsky et al., 2014). There may be unique relations between brain structure and IQ yet to be discovered that affect relevance for social-emotional function.

\section{Implication of Stability and Instability of IQ in ASD}

Variability in test scores represents a major observational finding of the current study. Although test scores across time within each domain were significantly and positively correlated, there was still considerable variability between time points. Individual test points can be identified and it is evident that some individuals in both groups exhibited variability in both directions (increasing or decreasing performance) on IQ testing over time. In our examination of individual stability, generally only half of all scores fell within the boundaries of either a $95 \% \mathrm{CI}$ or $\pm 0.5 \mathrm{SD}$. This suggests that an IQ estimate for an individual obtained at an early age may significantly differ from IQ at a later age. In our sample, we found that by early adulthood, verbal and working memory scores exhibit the greatest stability. In a practical and clinical sense, this suggests that a single VIQ test in adulthood may be sufficient to estimate function throughout adulthood, but the same is not true in childhood, particularly early childhood. This conclusion is consistent with the literature survey findings of Begovac et al. (2009) that by late childhood, IQ metrics are relatively stable. In contrast, nonverbal and perceptual organization scores continued to increase during adulthood in our ASD sample. Whether these findings represent practice effects or brain and cognitive maturation attributing to improved performance over time remains an important question. In healthy adults, memory scores can increase or decrease with repeated testing but 2 or more scores beyond a $90 \% \mathrm{CI}$ is not typical (Brooks et al., 2016). Our data suggest that, like other traits such as head circumference, intellectual functioning in ASD may be best understood by the longitudinal trajectory of multiple IQ points over time rather than any single IQ score at any one point in time. This finding has both research and clinical implications.

\section{Limitations and Future Directions}

The biggest limitation of our study, due to resources, was the focus on individuals with ASD who had IQs $\geq 70$, were verbally able, and male. We therefore do not know if our findings apply to females or to individuals with ASD who are also intellectually and verbally disabled. It is our hope that what we learn from our sample may eventually be relevant to these other very important groups. Our study findings are also limited in that our early childhood sample had a TDC group that was smaller and not IQ matched to the ASD group. This could have impacted our ability to estimate TDC trajectories during childhood and interpretation of group differences throughout the age range studied. Another limitation is the absence of detailed social, economic, and environmental history that may impact cognitive development and test performance.

There is also a major, but at the time unavoidable, limitation of the current study given that specific IQ and Index Scores varied between time points and were not uniformly administered. While a limitation, this is clinically realistic for professionals who evaluate and provide care for individuals with ASD across the lifespan and educators working with ASD students. It is possible that the different IQ metrics used to assess the youngest participants contributed to higher variability at earlier ages and potentially the lowest VIQ scores. For older individuals for whom only Wechsler versions were used, there is higher positive intercorrelation amongst versions than across task correlations with nonWechsler intellectual assessment methods, although all measures are positively and significantly correlated (Flanagan \& McDonough, 2018). Possibly the greater uniformity of the Wechsler-based procedures may have added to the stability of test scores observed in older childhood and adolescence through adulthood. The inclusion of a TDC group controls, in-part, for IQ test variation across the years of the study, because those TDC participants were taking the same tests at approximately the same times and intervals, especially when the participants were younger versus when they were older. Nonetheless, given known potential for test score inflation effects with IQ measures, the so-called "Flynn" effect (Kanaya \& Ceci, 2012, 2018), and given possible secular trends in IQ over time (Bratsberg \& Rogeberg, 2018), we have not likely been able to consider or statistically control for all variables that may have affected IQ in our longitudinal sample. However, for clinicians who examine, track and follow individuals with ASD, the findings presented herein do address some practical issues about the stability of IQ metrics from childhood into adulthood. 


\section{Conclusion}

This ISLA Utah Longitudinal Autism Study is the first to characterize intellectual functioning across multiple time points spanning early childhood to mid-adulthood. This investigation also has a research arm devoted to advanced MRI imaging analyses in ASD including diffusion tensor imaging, resting state functional connectivity mapping and standard structural neuroimaging (Alexander et al., 2007; J. S. Anderson et al., 2011; King et al., 2018; Lange et al., 2015; McLaughlin et al., 2018; Travers et al., 2015; Zielinski et al., 2012; Zielinski et al., 2014). This imaging is designed to probe the neural correlates of intellectual functioning in ASD and if they differ over time. Accordingly, the next step will be to examine these intellectual variables in ASD and TDC participants from a neurodevelopmental and neuroanatomical maturation perspective. Interesting findings relating important developmental parameters using brain imaging methods have begun with cross-sectional studies (Grydeland et al., 2019; Maier et al., 2018); however, the Utah sample will be particularly unique to further tease out the various brain-behavior relations based on a within subject longitudinal investigation to further our understanding between brain structure and function, IQ and autism (Hampshire et al., 2012). Additionally, the ISLA study has also obtained other neurocognitive, motor and neurobehavioral measures on this same ASD and TDC sample (Duffield et al., 2013; Green et al., 2016; Jantz et al., 2015; Travers et al., 2017). As mentioned in the Introduction, the "g" factor relations and their stability and/or variability between IQ and these other measures, while assumed to be similar for TDC, is unknown in ASD. Answers to these questions will be forthcoming.

Supplementary Information The online version contains supplementary material available at https://doi.org/10.1007/s10803-021-05227-x.

Acknowledgments The research reported in this publication was supported by the National Institutes of Mental Health of the National Institutes of Health under Award Number R01MH080826, a core grant to the Waisman Center from the National Institute of Child Health and Human Development (U54 HD090256) and utilized REDCap database services (8UL1TR000105, formerly UL1RR025764, NCATS/ $\mathrm{NIH})$. The content is solely the responsibility of the authors and does not necessarily represent the official views of the National Institutes of Health. There are no conflicts of interest to report. We thank former members of the Utah Collaborative Program of Excellence in Autism (CPEA), including Drs. Sally Ozonoff, Judith Miller, Mikle South, Jared Nielsen, Megan Farley, Michele Villalobos, Hilary Coon, and William McMahon. We also thank the individuals who participated in this study and their families.

Author Contributions MBDP contributed to the conceptualization, methodology, formal analysis, investigation, writing-original draft, visualization, data curation. EDB contributed to the conceptualization, methodology, writing - original draft, funding acquisition, supervision. NL contributed to the conceptualization, methodology, software, funding acquisition. JM contributed to the investigation, resources. AF contributed to the investigation, resources. KK contributed to the investigation, resources. KLK contributed to the investigation, methodology. CKK contributed to the investigation, resources. JT contributed to the investigation, resources. DCD III contributed to the software, formal analysis. JBK contributed to the investigation. JSA contributed to the funding acquisition. BAZ contributed to the conceptualization, funding acquisition. ALA contributed to the conceptualization, funding acquisition. JEL contributed to the conceptualization, investigation, writingoriginal draft, funding acquisition, supervision, project administration.

Funding The research leading to these results received funding from the National Institutes Health under award numbers R01 MH080826, U54 HD090256, and utilized services obtained from award 8UL1TR000105.

\section{Declarations}

Conflict of interest The authors have no relevant financial or non-financial interests to disclose.

Ethical Approval All study procedures were approved by the Institutional Review Board at the University of Utah. This study was performed in accordance with the ethical standards as laid down in the 1964 Declaration of Helsinki and its later amendments or comparable ethical standards.

Informed Consent Informed consent was obtained from all individual participants included in the study. For participants under age 18, consent was obtained from Parents or legal guardians and Assent from participants age 7-17 years. For those participants over age 18 with a legal guardian, written consent was obtained from the legal guardian and written Assent from the participant.

Research Involving Human Participants All study procedures were approved by the Institutional Review Board at the University of Utah. This study was performed in accordance with the ethical standards as laid down in the 1964 Declaration of Helsinki and its later amendments or comparable ethical standards.

Open Access This article is licensed under a Creative Commons Attribution 4.0 International License, which permits use, sharing, adaptation, distribution and reproduction in any medium or format, as long as you give appropriate credit to the original author(s) and the source, provide a link to the Creative Commons licence, and indicate if changes were made. The images or other third party material in this article are included in the article's Creative Commons licence, unless indicated otherwise in a credit line to the material. If material is not included in the article's Creative Commons licence and your intended use is not permitted by statutory regulation or exceeds the permitted use, you will need to obtain permission directly from the copyright holder. To view a copy of this licence, visit http://creativecommons.org/licenses/by/4.0/.

\section{References}

Akaike, H. (1974). A new look at the statistical model identification. IEEE Transactions on Automatic Control, 19(6), 716-723.

Akshoomoff, N. (2006). Use of the Mullen Scales of Early Learning for the assessment of young children with Autism Spectrum Disorders. Child Neuropsychology, 12(4-5), 269-277. https://doi.org/ 10.1080/09297040500473714 
Alexander, A. L., Lee, J. E., Lazar, M., Boudos, R., DuBray, M. B., Oakes, T. R., Miller, J. N., Lu, J., Jeong, E. K., McMahon, W. M., Bigler, E. D., \& Lainhart, J. E. (2007). Diffusion tensor imaging of the corpus callosum in Autism. NeuroImage, 34(1), 61-73. https://doi.org/10.1016/j.neuroimage.2006.08.032

American Psychiatric Association. (1994). Diagnostic and Statistical Manual of Mental Disorders: DSM-IV (4th ed.). American Psychiatric Association.

Anderson, D. K., Liang, J. W., \& Lord, C. (2014). Predicting young adult outcome among more and less cognitively able individuals with autism spectrum disorders. Journal of Child Psychology and Psychiatry, 55(5), 485-494. https://doi.org/10.1111/jcpp.12178

Anderson, J. S., Nielsen, J. A., Froehlich, A. L., DuBray, M. B., Druzgal, T. J., Cariello, A. N., Cooperrider, J. R., Zielinski, B. A., Ravichandran, C., Fletcher, P. T., Alexander, A. L., Bigler, E. D., Lange, N., \& Lainhart, J. E. (2011). Functional connectivity magnetic resonance imaging classification of autism. Brain, $134(\mathrm{Pt}$ 12), 3742-3754. https://doi.org/10.1093/brain/awr263

Begovac, I., Begovac, B., Majic, G., \& Vidovic, V. (2009). Longitudinal studies of IQ stability in children with childhood autism literature survey. Psychiatria Danubina, 21(3), 310-319.

Bigler, E. D. (2017). Structural neuroimaging in neuropsychology: History and contemporary applications. Neuropsychology, 31(8), 934-953. https://doi.org/10.1037/neu0000418

Bishop, S. L., Farmer, C., Bal, V., Robinson, E. B., Willsey, A. J., Werling, D. M., Havdahl, K. A., Sanders, S. J., \& Thurm, A. (2017). Identification of Developmental and Behavioral Markers Associated With Genetic Abnormalities in Autism Spectrum Disorder. American Journal of Psychiatry, 174(6), 576-585. https://doi.org/ 10.1176/appi.ajp.2017.16101115

Bishop, S. L., Farmer, C., \& Thurm, A. (2015). Measurement of nonverbal IQ in autism spectrum disorder: Scores in young adulthood compared to early childhood. Journal of Autism and Developmental Disorders, 45(4), 966-974. https://doi.org/10.1007/ s10803-014-2250-3

Bishop, S. L., Guthrie, W., Coffing, M., \& Lord, C. (2011). Convergent validity of the Mullen Scales of Early Learning and the differential ability scales in children with autism spectrum disorders. American Journal on Intellectual and Developmental Disabilities, 116(5), 331-343. https://doi.org/10.1352/1944-7558-116.5.331

Bishop, S. L., Richler, J., \& Lord, C. (2006). Association between restricted and repetitive behaviors and nonverbal IQ in children with autism spectrum disorders. Child Neuropsychology, 12(4-5), 247-267. https://doi.org/10.1080/09297040600630288

Bishop-Fitzpatrick, L., Mazefsky, C. A., Eack, S. M., \& Minshew, N. J. (2017). Correlates of Social Functioning in Autism Spectrum Disorder: The Role of Social Cognition. Research in Autism Spectrum Disorder, 35, 25-34. https://doi.org/10.1016/j.rasd.2016.11.013

Bratsberg, B., \& Rogeberg, O. (2018). Flynn effect and its reversal are both environmentally caused. Proc Natl Acad Sci U S A, 115(26), 6674-6678. https://doi.org/10.1073/pnas.1718793115

Brooks, B. L., Holdnack, J. A., \& Iverson, G. L. (2016). To Change is Human: "Abnormal" Reliable Change Memory Scores are Common in Healthy Adults and Older Adults. Archives of Clinical Neuropsychology, 31(8), 1026-1036. https://doi.org/10.1093/ arclin/acw079

Canivez, G. L., Watkins, M. W., \& Dombrowski, S. C. (2017). Structural validity of the Wechsler Intelligence Scale for Children-Fifth Edition: Confirmatory factor analyses with the 16 primary and secondary subtests. Psychological Assessment, 29(4), 458-472. https://doi.org/10.1037/pas0000358

Charman, T., Loth, E., Tillmann, J., Crawley, D., Wooldridge, C., Goyard, D., Ahmad, J., Auyeung, B., Ambrosino, S., Banaschewski, T., Baron-Cohen, S., Baumeister, S., Beckmann, C., Bölte, S., Bourgeron, T., Bours, C., Brammer, M., Brandeis, D., Brogna, C., ...Buitelaar, J. K. (2017). The EU-AIMS
Longitudinal European Autism Project (LEAP): clinical characterisation. Molucular Autism, 8, 27. https://doi.org/10.1186/ s13229-017-0145-9

Charman, T., Pickles, A., Simonoff, E., Chandler, S., Loucas, T., \& Baird, G. (2011). IQ in children with autism spectrum disorders: Data from the Special Needs and Autism Project (SNAP). Psychological Medicine, 41(3), 619-627. https://doi.org/10.1017/S0033 291710000991

Deary, I. J. (2012). Intelligence. Annual Review of Psychology, 63(1), 453-482. https://doi.org/10.1146/annurev-psych-120710-100353

Deutsch, C. K., \& Joseph, R. M. (2003). Brief report: Cognitive correlates of enlarged head circumference in children with autism. Journal of Autism and Developmental Disorders, 33(2), 209-215. https://doi.org/10.1023/a:1022903913547

Duffield, T. C., Trontel, H. G., Bigler, E. D., Froehlich, A., Prigge, M. B., Travers, B., Green, R. R., Cariello, A. N., Cooperrider, J., Nielsen, J., Alexander, A., Anderson, J., Fletcher, P. T., Lange, N., Zielinski, B., \& Lainhart, J. (2013). Neuropsychological investigation of motor impairments in autism. Journal of Clinical and Experimental Neuropsychology, 35(8), 867-881. https://doi.org/ 10.1080/13803395.2013.827156

Elliott, C. D. (1990). Differential Ability Scales: Introductory and Technical Handbook. The Psychological Corporation.

Farley, M. A., McMahon, W. M., Fombonne, E., Jenson, W. R., Miller, J., Gardner, M., Block, H., Pingree, C. B., Ritvo, E. R., Ritvo, R. A., \& Coon, H. (2009). Twenty-year outcome for individuals with autism and average or near-average cognitive abilities. Autism Research, 2(2), 109-118. https://doi.org/10.1002/aur.69

Farrington, D. P. (1991). Longitudinal research strategies: Advantages, problems, and prospects. Journal of the American Academy of Child and Adolescent Psychiatry, 30(3), 369-374. https://doi.org/ 10.1097/00004583-199105000-00003

Flanagan, D. P., \& McDonough, E. M. (2018). Contemporary Intellectual Assessment; Theories, Tests and Issues (4th ed.). Guilford Press.

Galton, F. (1889). Natural Inheritance. Macmillan.

Green, R. R., Bigler, E. D., Froehlich, A., Prigge, M. B., Travers, B. G., Cariello, A. N., Anderson, J. S., Zielinski, B. A., Alexander, A., Lange, N., \& Lainhart, J. E. (2016). Beery VMI performance in autism spectrum disorder. Child Neuropsychology, 22(7), 795817. https://doi.org/10.1080/09297049.2015.1056131

Grydeland, H., Vertes, P. E., Vasa, F., Romero-Garcia, R., Whitaker, K., Alexander-Bloch, A. F., Bjørnerud, A., Patel, A. X., Sederevičius, D., Tamnes, C. K., Westlye, L. T., White, S. R., Walhovd, K. B., Fjell, A. M., \& Bullmore, E. T. (2019). Waves of Maturation and Senescence in Micro-structural MRI Markers of Human Cortical Myelination over the Lifespan. Cerebral Cortex, 29(3), 1369-1381. https://doi.org/10.1093/cercor/bhy330

Hampshire, A., Highfield, R. R., Parkin, B. L., \& Owen, A. M. (2012). Fractionating human intelligence. Neuron, 76(6), 1225-1237. https://doi.org/10.1016/j.neuron.2012.06.022

Hartshorne, J. K., \& Germine, L. T. (2015). When does cognitive functioning peak? The asynchronous rise and fall of different cognitive abilities across the life span. Psychological Science, 26(4), 433-443. https://doi.org/10.1177/0956797614567339

Hinton-Bayre, A. D. (2016). Clarifying Discrepancies in Responsiveness Between Reliable Change Indices. Archives of Clinical Neuropsychology. https://doi.org/10.1093/arclin/acw064

Howlin, P., Goode, S., Hutton, J., \& Rutter, M. (2004). Adult outcome for children with autism. Journal of Child Psychology and Psychiatry, 45(2), 212-229. https://doi.org/10.1111/j.1469-7610. 2004.00215.x

Howlin, P., Moss, P., Savage, S., \& Rutter, M. (2013). Social outcomes in mid- to later adulthood among individuals diagnosed with autism and average nonverbal IQ as children. Journal of the 
American Academy of Child \& Adolescent Psychiatry, 52(6), 572581 e571. https://doi.org/10.1016/j.jaac.2013.02.017

Howlin, P., Savage, S., Moss, P., Tempier, A., \& Rutter, M. (2014). Cognitive and language skills in adults with autism: A 40-year follow-up. Journal of Child Psychology and Psychiatry, 55(1), 49-58. https://doi.org/10.1111/jcpp.12115

Hus, V., Gotham, K., \& Lord, C. (2014). Standardizing ADOS domain scores: Separating severity of social affect and restricted and repetitive behaviors. Journal of Autism and Developmental Disorders, 44(10), 2400-2412. https://doi.org/10.1007/s 10803-012-1719-1

Hus, V., \& Lord, C. (2014). The autism diagnostic observation schedule, module 4: Revised algorithm and standardized severity scores. Journal of Autism and Developmental Disorders, 44(8), 1996-2012. https://doi.org/10.1007/s10803-014-2080-3

Jantz, P. B., Froehlich, A. L., Cariello, A. N., Anderson, J., Alexander, A. L., Bigler, E. D., Prigge, M. B., Travers, B. G., Zielinski, B. A., Lange, N., \& Lainhart, J. E. (2015). Wide Range Achievement Test in Autism Spectrum Disorder: Test-Retest Stability. Psychological Report, 116(3), 674-684. https://doi.org/10.2466/ 03.15.PR0.116k24w8

Joseph, R. M., Tager-Flusberg, H., \& Lord, C. (2002). Cognitive profiles and social-communicative functioning in children with autism spectrum disorder. Journal of Child Psychology and Psychiatry, 43(6), 807-821. https://doi.org/10.1111/1469-7610.00092

Kanaya, T., \& Ceci, S. (2012). The impact of the Flynn effect on LD diagnoses in special education. Journal of Learning Disabilities, 45(4), 319-326. https://doi.org/10.1177/0022219410392044

Kanaya, T., \& Ceci, S. J. (2018). Longitudinal IQ Trends in Children Diagnosed with Emotional Disturbance: An Analysis of Historical Data. Journal of Intelligence. https://doi.org/10.3390/jintellige nce6040045

King, J. B., Prigge, M. B. D., King, C. K., Morgan, J., Dean, D. C., 3rd., Freeman, A., Villaruz, J. A. M., Kane, K. L., Bigler, E. D., Alexander, A. L., Lange, N., Zielinski, B. A., Lainhart, J. E., \& Anderson, J. S. (2018). Evaluation of Differences in Temporal Synchrony Between Brain Regions in Individuals With Autism and Typical Development. JAMA Network Open, 1(7), e184777. https://doi.org/10.1001/jamanetworkopen.2018.4777

Kraper, C. K., Kenworthy, L., Popal, H., Martin, A., \& Wallace, G. L. (2017). The Gap Between Adaptive Behavior and Intelligence in Autism Persists into Young Adulthood and is Linked to Psychiatric Co-morbidities. Journal of Autism and Developmental Disorders, 47(10), 3007-3017. https://doi.org/10.1007/ s10803-017-3213-2

Lainhart, J. E., Bigler, E. D., Bocian, M., Coon, H., Dinh, E., Dawson, G., Deutsch, C. K., Dunn, M. D., Estes, A., Tager-Flusberg, H., Folstein, S., Hepburn, S., Hyman, S., McMahon, W., Minshew, N., Munson, J., Osann, K., Ozonoff, S., Rodier, P., ...Volkmar, F. (2006). Head circumference and height in autism: a study by the Collaborative Program of Excellence in Autism. American Journal of Medical Genetics. Part A, 140(21), 2257-2274. https://doi. org/10.1002/ajmg.a.31465

Laird, N. M., \& Ware, J. H. (1982). Random-effects models for longitudinal data. Biometrics, 38(4), 963-974.

Lange, N., Froimowitz, M. P., Bigler, E. D., Lainhart, J. E., \& Brain Development Cooperative Group. (2010). Associations between IQ, total and regional brain volumes, and demography in a large normative sample of healthy children and adolescents. Developmental Neuropsychology, 35(3), 296-317. https://doi.org/10.1080/ 87565641003696833

Lange, N., \& Laird, N. M. (1989). The effect of covariance structure on variance estimation in balanced growth curve models with random parameters. Journal of the American Statistical Association, 84(405), 241-247.

Lange, N., Travers, B. G., Bigler, E. D., Prigge, M. B., Froehlich, A. L., Nielsen, J. A., Cariello, A. N., Zielinski, B. A., Anderson, J.
S., Fletcher, P. T., Alexander, A. A., \& Lainhart, J. E. (2015). Longitudinal volumetric brain changes in autism spectrum disorder ages 6-35 years. Autism Research, 8(1), 82-93. https://doi. org/10.1002/aur.1427

Lezak, M. D., Howieson, D. B., Bigler, E. D., \& Tranel, D. (2012). Neuropsychological assessment (5th ed.). Oxford University Press.

Lord, C., Bishop, S., \& Anderson, D. (2015). Developmental trajectories as autism phenotypes. American Journal of Medical Genetics. Part C, Seminars in Medical Genetics, 169(2), 198-208. https:// doi.org/10.1002/ajmg.c.31440

Lord, C., McCauley, J. B., Pepa, L. A., Huerta, M., \& Pickles, A. (2020). Work, living, and the pursuit of happiness: Vocational and psychosocial outcomes for young adults with autism. Autism, 24(7), 1691-1703. https://doi.org/10.1177/1362361320919246

Lord, C., Rutter, M., DiLavore, P. C., \& Risi, S. (1999). Autism diagnostic observation schedule: Manual. Western Psychological Services.

Lord, C., Rutter, M., DiLavore, P. C., Risi, S., Gotham, K., \& Bishop, S. (2012). Autism Diagnostic Observation Schedule, second edition (ADOS-2), manual (Part 1). Modules 1-4. Western Psychological Services.

Lord, C., Rutter, M., \& Le Couteur, A. (1994). Autism Diagnostic Interview-Revised: a revised version of a diagnostic interview for caregivers of individuals with possible pervasive developmental disorders. Journal of Autism and Developmental Disorders, 24(5), 659-685.

Maassen, G. H., Bossema, E., \& Brand, N. (2009). Reliable change and practice effects: Outcomes of various indices compared. Journal of Clinical and Experimental Neuropsychology, 31(3), 339-352. https://doi.org/10.1080/13803390802169059

Magiati, I., Tay, X. W., \& Howlin, P. (2014). Cognitive, language, social and behavioural outcomes in adults with autism spectrum disorders: A systematic review of longitudinal follow-up studies in adulthood. Clinical Psychology Review, 34(1), 73-86. https:// doi.org/10.1016/j.cpr.2013.11.002

Maier, S., Tebartz van Elst, L., Perlov, E., Duppers, A. L., Nickel, K., Fangmeier, T., Endres, D., \& Riedel, A. (2018). Cortical properties of adults with autism spectrum disorder and an IQ $>100$. Psychiatry Res Neuroimaging, 279, 8-13. https://doi.org/10. 1016/j.pscychresns.2018.06.013

Martos-Perez, J., Freire-Prudencio, S., Llorente-Comi, M., AyudaPascual, R., \& Gonzalez-Navarro, A. (2018). Autism and intelligence quotient: stability? Revista De Neurologia, 66(S01), S39-S44.

Mayes, S. D., \& Calhoun, S. L. (2003). Ability profiles in children with autism: Influence of age and IQ. Autism, 7(1), 65-80. https://doi. org/10.1177/1362361303007001006

Mayes, S. D., Calhoun, S. L., Murray, M. J., \& Zahid, J. (2011). Variables associated with anxiety and depression in children with autism. Journal of Developmental and Physical Disabilities, 23(4), 325-337. https://doi.org/10.1007/s10882-011-9231-7

Mazefsky, C. A., Borue, X., Day, T. N., \& Minshew, N. J. (2014). Emotion regulation patterns in adolescents with high-functioning autism spectrum disorder: Comparison to typically developing adolescents and association with psychiatric symptoms. Autism Research, 7(3), 344-354. https://doi.org/10.1002/aur.1366

McLaughlin, K., Travers, B. G., Dadalko, O. I., Dean, D. C., 3rd., Tromp, D., Adluru, N., Destiche, D., Freeman, A., Prigge, M. D., Froehlich, A., Duffield, T. C., Zielinski, B. A., Bigler, E. D., Lange, N., Anderson, J. S., Alexander, A. L., \& Lainhart, J. E. (2018). Longitudinal development of thalamic and internal capsule microstructure in autism spectrum disorder. Autism Research, 11(3), 450-462. https://doi.org/10.1002/aur.1909

Morrison, K. E., Pinkham, A. E., Kelsven, S., Ludwig, K., Penn, D. L., \& Sasson, N. J. (2019). Psychometric Evaluation of Social 
Cognitive Measures for Adults with Autism. Autism Research, 12(5), 766-778. https://doi.org/10.1002/aur.2084

Mullen, E. M. (1995). Mullen Scales of Early Learning (AGS Edition). Pearson.

Nordin, V., \& Gillberg, C. (1998). The long-term course of autistic disorders: Update on follow-up studies. Acta Psychiatrica Scandinavia, 97(2), 99-108. https://doi.org/10.1111/j.1600-0447.1998. tb09970.x

Pallathra, A. A., Calkins, M. E., Parish-Morris, J., Maddox, B. B., Perez, L. S., Miller, J., Gur, R. C., Mandell, D. S., Schultz, R. T., \& Brodkin, E. S. (2018). Defining behavioral components of social functioning in adults with autism spectrum disorder as targets for treatment. Autism Research, 11(3), 488-502. https://doi. org/10.1002/aur.1910

Pickles, A., McCauley, J. B., Pepa, L. A., Huerta, M., \& Lord, C. (2020). The adult outcome of children referred for autism: Typology and prediction from childhood. Journal of Child Psychology and Psychiatry, 61(7), 760-767. https://doi.org/10.1111/jcpp. 13180

Pinheiro, J., Bates, D., DebRoy, S., Sarkar, D., \& R Core Team. (2017). nlme: Linear and Nonlinear Mixed Effects Models. R package version 3.1-131. Retrieved April 4, 2021, from https://CRAN.R-proje ct.org/package $=$ nlme.

Prigge, M. D., Bigler, E. D., Fletcher, P. T., Zielinski, B. A., Ravichandran, C., Anderson, J., Froehlich, A., Abildskov, T., Papadopolous, E., Maasberg, K., Nielsen, J. A., Alexander, A. L., Lange, N., \& Lainhart, J. (2013). Longitudinal Heschl's gyrus growth during childhood and adolescence in typical development and autism. Autism Research, 6(2), 78-90. https://doi.org/10.1002/aur.1265

R Core Team. (2017). R: A language and environment for statistical computing. R Foundation for Statistical Computing, Vienna, Austria. Retrieved April 4, 2021, from https://www.R-project.org/.

Rinaldi, L., \& Karmiloff-Smith, A. (2017). Intelligence as a Developing Function: A Neuroconstructivist Approach. Journal of Intelligence. https://doi.org/10.3390/jintelligence5020018

Salthouse, T. A. (2016). Little relation of adult age with cognition after controlling general influences. Developmental Psychology, 52(10), 1545-1554. https://doi.org/10.1037/dev0000162

Salthouse, T. A. (2019). Comparable Consistency, Coherence, and Commonality of Measures of Cognitive Functioning Across Adulthood. Assessment, 26(4), 726-736. https://doi.org/10.1177/ 1073191117721742

Salthouse, T. A. (2019). Trajectories of normal cognitive aging. Psychology and Aging, 34(1), 17-24. https://doi.org/10.1037/pag00 0028

Simonoff, E., Kent, R., Stringer, D., Lord, C., Briskman, J., Lukito, S., Pickles, A., Charman, T., \& Baird, G. (2019). Trajectories in Symptoms of Autism and Cognitive Ability in Autism From Childhood to Adult Life: Findings From a Longitudinal Epidemiological Cohort. Journal of the American Academy of Child and Adolescent Psychiatry. https://doi.org/10.1016/j.jaac.2019.11.020

Solomon, M., Iosif, A. M., Reinhardt, V. P., Libero, L. E., Nordahl, C. W., Ozonoff, S., Rogers, S. J., \& Amaral, D. G. (2018). What will my child's future hold? phenotypes of intellectual development in 2-8-year-olds with autism spectrum disorder. Autism Research, 11(1), 121-132. https://doi.org/10.1002/aur.1884

Southwick, J. S., Bigler, E. D., Froehlich, A., DuBray, M. B., Alexander, A. L., Lange, N., \& Lainhart, J. E. (2011). Memory functioning in children and adolescents with autism. Neuropsychology, 25(6), 702-710. https://doi.org/10.1037/a0024935

Stewart, S. L., Falah Hassani, K., Poss, J., \& Hirdes, J. (2017). The determinants of service complexity in children with intellectual disabilities. Journal of Intellectual Disability Research, 61(11), 1055-1068. https://doi.org/10.1111/jir.12423

Tillmann, J., San José Cáceres, A., Chatham, C. H., Crawley, D., Holt, R., Oakley, B., Banaschewski, T., Baron-Cohen, S., Bölte, S.,
Buitelaar, J. K., Durston, S., Ham, L., Loth, E., Simonoff, E., Spooren, W., Murphy, D. G., Charman, T., \& EU-AIMS LEAP group. (2019). Investigating the factors underlying adaptive functioning in autism in the EU-AIMS Longitudinal European Autism Project. Autism Research, 12(4), 645-657. https://doi.org/10.1002/ aur.2081

Travers, B. G., Bigler, E. D., Duffield, T. C., Prigge, M. D. B., Froehlich, A. L., Lange, N., Alexander, A. L., \& Lainhart, J. E. (2017). Longitudinal development of manual motor ability in autism spectrum disorder from childhood to mid-adulthood relates to adaptive daily living skills. Developmental Science. https://doi.org/ $10.1111 /$ desc. 12401

Travers, B. G., Bigler, E. D., Tromp, D. P. M., Adluru, N., Froehlich, A. L., Ennis, C., Lange, N., Nielsen, J. A., Prigge, M. B., Alexander, A. L., \& Lainhart, J. E. (2014). Longitudinal processing speed impairments in males with autism and the effects of white matter microstructure. Neuropsychologia, 53, 137-145. https://doi.org/ 10.1016/j.neuropsychologia.2013.11.008

Travers, B. G., Tromp, D. P. M., Adluru, N., Lange, N., Destiche, D., Ennis, C., Nielsen, J. A., Froehlich, A. L., Prigge, M. B., Fletcher, P. T., Anderson, J. S., Zielinski, B. A., Bigler, E. D., Lainhart, J. E., \& Alexander, A. L. (2015). Atypical development of white matter microstructure of the corpus callosum in males with autism: a longitudinal investigation. Molecular Autism, 6, 15. https://doi.org/10.1186/s13229-015-0001-8

Tureck, K., Matson, J. L., Cervantes, P., \& Konst, M. J. (2014). An examination of the relationship between autism spectrum disorder, intellectual functioning, and comorbid symptoms in children. Research in Developmental Disabilities, 35(7), 1766-1772. https://doi.org/10.1016/j.ridd.2014.02.013

Wechsler, D. (1991). Wechsler Intelligence Scale for Children - Third Edition (WISC-III). The Psychological Corporation.

Wechsler, D. (1997). Wechsler Adult Intelligence Scale - Third Edition (WAIS-III). The Psychological Corporation.

Wechsler, D. (1999). Wechsler Abbreviated Scale of Intelligence (WASI). The Psychological Corporation.

Wechsler, D. (2008). Wechsler Adult Intelligence Scale-Fourth Edition (WAIS-IV). Pearson.

Willett, J. B., Singer, J. D., \& Martin, N. C. (1998). The design and analysis of longitudinal studies of development and psychopathology in context: Statistical models and methodological recommendations. Development and Psychopathology, 10(2), 395-426. https://doi.org/10.1017/s0954579498001667

Wolak, M. E., Fairbairn, D. J., \& Paulsen, Y. R. (2012). Guidelines for Estimating Repeatability. Methods in Ecology and Evolution, 3(1), 129-137.

Zielinski, B. A., Anderson, J. S., Froehlich, A. L., Prigge, M. B., Nielsen, J. A., Cooperrider, J. R., Cariello, A. N., Fletcher, P. T., Alexander, A. L., Lange, N., Bigler, E. D., \& Lainhart, J. E. (2012). scMRI reveals large-scale brain network abnormalities in autism. PLoS ONE, 7(11), e49172. https://doi.org/10.1371/journ al.pone.0049172

Zielinski, B. A., Prigge, M. B., Nielsen, J. A., Froehlich, A. L., Abildskov, T. J., Anderson, J. S., Fletcher, P. T., Zygmunt, K. M., Travers, B. G., Lange, N., Alexander, A. L., Bigler, E. D., \& Lainhart, J. E. (2014). Longitudinal changes in cortical thickness in autism and typical development. Brain, 137(Pt 6), 1799-1812. https:// doi.org/10.1093/brain/awu083

Publisher's Note Springer Nature remains neutral with regard to jurisdictional claims in published maps and institutional affiliations. 